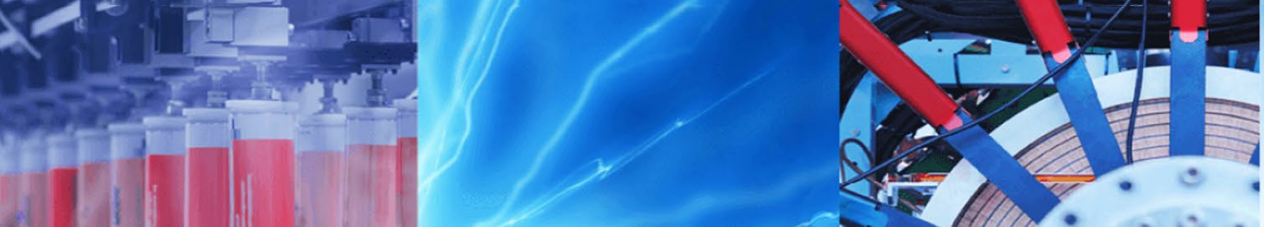

Research Article

\title{
Ultra-high-performance cementitious composites with enhanced mechanical and durability characteristics
}

\author{
Muhammad M. Sadiq ${ }^{1} \cdot$ Parviz Soroushian $^{1} \cdot$ Martin G. Bakker $^{2} \cdot$ Anagi M. Balachandra $^{1}$ (I) \\ Received: 8 October 2020 / Accepted: 4 May 2021 \\ Published online: 30 May 2021 \\ (c) The Author(s) $2021 \quad$ OPEN
}

\begin{abstract}
Concrete is the most widely used construction material. It offers a desirable balance of cost, strength, moisture barrier qualities, and dimensional and chemical stability. The rising costs of aging infrastructure systems, however, point to the need for further improvements in concrete properties. Carbon-based nanomaterials (CBNs) are predicted to have excellent mechanical properties, and so are attractive candidates for addressing these issues. However, the relatively high cost of $\mathrm{CBNs}$, means that only low weight fractions in cement matrices will be economically viable, which presents a significant challenge. The research presented here investigated various surface functionalization techniques for improving the compatibility of carbon nanomaterials (multi-walled carbon nanotubes, carbon nanofiber and graphene nanoplatelets) with cementitious materials in fresh and hardened state. The effects of surface functionalization on the contributions of CBNs to the performance characteristics of ultra-high-performance cementitious matrices (UHPCM) were evaluated. Functionalized multi-walled carbon nanotubes at $0.03 \%$ weight fraction increased the flexural strength by $30 \%$, doubled the energy absorption capacity, and tripled the ductility of UHPCM. The moisture barrier qualities, abrasion resistance and toughness characteristics of UHPCM benefited significantly from introduction of CBNs at less than $0.1 \%$ weight fraction. This study demonstrates that the low weight fraction of CBNs can effectively enhance the key engineering properties of UHPCM at a viable cost. Thus, this approach has both performance advantages and economic benefits.
\end{abstract}

\section{Article highlights}

- Surface functionalization of multiwalled CNTs improved dispersion in cementitious matrices at low weight fractions.

- 0.03 wt.\% multiwalled CNT addition increased the flexural strength and the flexural toughness of UHPCM.

- Abrasion resistance and moisture barrier qualities improved.

- These improvements are achieved at viable cost.

Keywords Surface functionalized carbon nanomaterials · Ultra-high-performance cementitious matrices · Abrasion resistance $\cdot$ Moisture barrier qualities $\cdot$ Ductility $\cdot$ Flexural strength

Supplementary Information The online version contains supplementary material available at https://doi.org/10.1007/s42452-021-04628$y$.

$\triangle$ Anagi M. Balachandra, abmetnaco@gmail.com | ${ }^{1}$ Metna Company, 1926 Turner Street, Lansing, MI 48906, USA. ${ }^{2}$ Department of Chemistry and Biochemistry, The University of Alabama, Tuscaloosa, AL 35487-0336, USA.

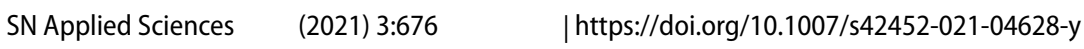




\section{Introduction}

Cement- and concrete-based materials (CCBMs) offer suitable engineering properties such as compressive strength, moisture resistance and durability at low cost, combined with energy saving and environmental benefits. In the global context, CCBM is the most widely used class of manufactured materials. However, CCBM lack adequate toughness, and tensile strength; further improvement of their durability in aggressive environments would also yield major benefits in terms of the life-cycle cost of infrastructure systems [1-4].

Utilization of nanomaterials alone or in combination with microfibers can significantly benefit the structural performance, durability and safety of cement-based products [5-12]. Out of the many available nanomaterials carbon-based nanomaterials (CBNs) are especially attractive in cement matrices because of their distinct mechanical and physical attributes as well as enormous surface areas even at low weight fractions [13-15]. Carbon nanotubes (CNTs), owing to their high-aspect ratio and large specific surface area they have the ability to mitigate propagating cracks [16], improving the mechanical properties.

Mechanical performance, fracture characteristics, and the durability of cementitious composites could be significantly enhanced by incorporating the high tensile strength and high toughness of CBNs [17, 18]. Various CBNs including carbon nanofibers (CNFs) [9, 19-21], carbon nanotubes (CNTs) [22-27] and graphene nanoplatelets (GNPs) [21, 28-31]. Previous results indicated that adding CNTs $0.05 \%-2 \%$ by weight of cement can improve mechanical properties including flexural strength, fracture energy, compressive strength, and toughness [10, 32-41]. Shah et al. [42] and Konsta-Gdoutos et al. [16, 43] studied the effect of multi-walled carbon nanotubes (MWNTs) on the fracture properties of the nanocomposites and found a $25 \%$ increase in flexural strength by incorporating $0.048-0.08 \%$ of MWNT by weight of cement. Ruan et. al [34] incorporated four types of MWNTs with weight fractions of $0.25 \%-0.5 \%$ into reactive powder concrete (RPC) and demonstrated that MWNTs can effectively improve flexural strength, fracture energy, compressive strength/toughness ratio and flexural strength/compressive strength ratio of RPC. Hybrid graphene oxide (GO)/ CNTs, with the dosage of $0.05 \%$ by weight of cement and GO:CNTs mass ratio of 3:2, improved the compressive strength by $45 \%$, which showed better reinforcing effects than the single addition of GO and CNTs with the same dosage respectively [28]. However, due to the large surface to volume ratios of nanomaterials, their uniform dispersion is a challenge $[16,32,44]$. The high surface area of nanomaterials and hydrophobic nature of the surface generates strong tendencies towards agglomeration through van der Waals forces, preventing their effective use as reinforcements $[42,45,46]$. Further, the largely inert surfaces of CBNs offer limited potential for chemical bonding to cement hydrates.

Studies have attempted to improve dispersion of carbon based nanomaterials through various chemical modifications of the nanomaterial walls $[35,38,47-49]$ and physical modifications through use of surfactants $[16,41$, 50-54]; admixtures [55]; polycarboxylic-based superplasticizers $[56,57]$; and other dispersing agents $[23,26,51,58$, 59]. CNT synthesized via plasma processing was demonstrated to produce better dispersions in high performance cement based composites and improved mechanical properties at $0.068 \%$ by weight of cement [60]. Zhan et al. synthesized CNTs in situ on the surface of fly ash (FA) to improve the CNT dispersibility and the resulting cement mortar exhibited an outstanding strain-sensing capability at 2.0 wt.\% [44]. However, utilizing the full benefit of CBNs at low dosages as reinforcing fillers in high performance cementitious composites is still an ongoing challenge.

This study focuses on further reducing the weight fractions of CBNs in Ultra-High Performance cementitious matrices (UHPCM) through improving the dispersibility by introduction of surface functional groups tethered on nanomaterial walls. These surface functional groups are compatible with cement hydrates, thereby improving the interfacial interactions of nanomaterials with UHPCM [61]. This study demonstrates that proper surface functionalization and uniform dispersion of CBNs (CNTs, and CNFs) brings about improvements in key properties of cement-based materials at weight fractions as low as $0.03 \%$ by weight of cement. Utilization of low weight fraction of CBNs is very appealing considering the cost of nanomaterials and that cement is a high-volume application, and so will have economic benefits.

This study also emphasizes lower-cost $\mathrm{CBN}_{\mathrm{S}}$ (particularly graphene nanoplatelets (GNPs)) that have so far received less attention as reinforcement/additive in CCBMs. Uniformly dispersed GNPs in UHPCM were used to enhance moisture barrier qualities in cementitious matrices. This is especially important for niche applications [5] and would also yield major benefits in terms of the life-cycle cost of infrastructure systems. Another significant aspect of the current work is incorporation of functionalized CBNs to show improvements in abrasion resistance in UHPCM. To the best of our knowledge little attention has been given to the benefits of utilizing CBNs to improve durability and resistance to wear in cementitious matrices.

The work presented here demonstrates the integration of UHPCM and effective use of the unique geometric and 
Table 1 Chemical composition of type I Portland cement

\begin{tabular}{ll}
\hline $\begin{array}{l}\text { Chemical com- } \\
\text { position }\end{array}$ & Percentage \\
\hline $\mathrm{CaO}$ & 62 \\
$\mathrm{SiO}_{2}$ & 22 \\
$\mathrm{Al}_{2} \mathrm{O}_{3}$ & 5 \\
$\mathrm{CaSO}_{4}$ & 4 \\
$\mathrm{MgO}$ & 2 \\
$\mathrm{~S}$ & 1 \\
Other & 1 \\
\hline
\end{tabular}

mechanical attributes of surface modified CBNs at low weight fractions towards achieving desirable combinations of mechanical performance and durability suitable for demanding fields of application.

\section{Materials and methods}

Type I Portland cement (ASTM C150 [62], Normal, Ordinary Portland Cement, OPC, particle size in the range of 1-50 $\mu \mathrm{m})$, obtained from Lafarge-North America was used in the study (chemical composition is given in Table 1). Silica fume was acquired from Norchem, Inc. It comprises nano-scale (200 $\mathrm{nm}$ average particle size) amorphous silica particles, with a minimum silicon dioxide content of $85 \%$ and a specific gravity of 2.25 . The specific surface area of this silica fume is $15 \mathrm{~m}^{2} / \mathrm{g}$, and its minimum 7-day pozzolanic activity index is $105 \%$. Polycarboxylate-based superplasticizer, Glenium ${ }^{\circledast} 7700$ (BASF) was used. Superplasticizer, Glenium ${ }^{\oplus} 7700$ is a high-range water reducer that has excellent slump retention without compromising early-age compressive strength development and set time. Glenium ${ }^{\circledast} 7700$ meets the ASTM C494 requirements for Type $F$ (high-range water-reducing) admixtures.

CBNs; different types of acid-functionalized and nonfunctionalized MWNTs, oxidized CNFs (CNF-OX) (60-150 $\mathrm{nm}$ in diameter and 30-100 $\mu \mathrm{m}$ in length) (Pyrograf ${ }^{\oplus}-1 \mathrm{II}$, Grade PR 24-XT-PS OX from Pyrograf Products, Inc.) and GNPs (6-8 nm thickness and about $15 \mu \mathrm{m}$ planar dimensions) (from XG Sciences Inc.) were evaluated in UHPCM based nanocomposites. Two different types of MWNTs were used. MWNT-A and MWNT-B were obtained from NanoAmor Inc. MWNT-A with an outer diameter of 20-40 $\mathrm{nm}$, core diameter of 5-10 nm and length of 5-15 $\mu \mathrm{m}$. MWNT-B with an outer diameter of $60-100 \mathrm{~nm}$, core diameter of 5-10 nm and length of 5-15 $\mu \mathrm{m}$.

Two previously established procedures were used for introduction of carboxylic acid functional groups $(\mathrm{COOH})$ onto carbon nanomaterials: (i) oxidation with strong oxidizing acids (MWNT A-OX, MWNT B-OX and CNF-OX) [63]; and (ii) fluorination followed by ethyl carboxylation
(F-MWNT A-COOH and F-MWNT B-COOH) [61]. Surface functionalized carbon nanomaterial dispersions were prepared via sonication following previously established procedures [61]. The sonication (Fisher Scientific 500 Sonic Dismembrator, power $100 \mathrm{~W}$, frequency $20 \mathrm{kHz}$ ) procedure is briefly described as follows: (i) turn on the probe for 10 min at each.

amplitude starting from $30 \%$ and then increasing the amplitude in ascending order, $45 \%, 65 \%$ and $75 \%$ and 1 -min breaks in between; (ii) at $85 \%$ amplitude $1 \mathrm{~min}$ on and $30 \mathrm{~s}$ off for $10 \mathrm{~min}$; and (iii) turn the probe off for $2 \mathrm{~min}$. Then steps (i)-(iii) were repeated twice. The same procedure was used for all carbon nanomaterials. The carbon nanomaterial dispersions were used as the mixing water for the cement paste specimens.

\subsection{Experimental methods}

Cementitious materials (with and without functionalized CBNs dispersed in the mixing water via sonication) were prepared following the ASTM C192 [64] and ASTM C305 [65] procedures. The UHPCM specimens were prepared as follows (relative proportions are given in Table 2): (i) mix cement and silica fume for 3 min at speed 1 in a mortar mixer (HOBART, Model A200F); (ii) add water (with dispersed carbon nanomaterial, if any, at the concentration required to yield the targeted weight fraction) plus superplasticizer, and mix for approximately $2 \mathrm{~min}$ at each of the speeds 1, 2 and 3; (iii) cast specimens following ASTM C192 procedures, using a vibrating table (FMC Syntron Power Plus) at vibration intensity of 10 .

The specimens were cured inside molds after casting (ASTM C192) over a 24-h period at room temperature $\left(23^{\circ} \mathrm{C}\right)$ and relative humidity $50 \%$. Samples were then demolded and subjected to $48 \mathrm{~h}$ of steam curing at 70 ${ }^{\circ} \mathrm{C}$. Steam curing at $70^{\circ}-90^{\circ} \mathrm{C}$ substantially accelerates the pozzolanic reaction, while modifying the microstructure of the hydrates which have formed [66]. However, for our experimental regimen $70^{\circ} \mathrm{C}$ was selected to minimize the energy requirement for production of UHPCM. The samples were subsequently conditioned at $50 \%$ relative humidity for seven days prior to testing.

Table 2 The composition of the cementitious matrix selected for evaluation of the reinforcement efficiency of CBNs

\begin{tabular}{ll}
\hline Mix proportions & UHPCM \\
\hline Silica Fume/Binder & 0.20 \\
Water/Binder & 0.185 \\
Superplasticizer/Binder & $\begin{array}{c}0.018-0.02 \text { (Adjusted } \\
\text { for different reinforce- } \\
\text { ment) }\end{array}$ \\
\hline
\end{tabular}




\subsection{Materials characterization}

The following experimental methods were used to gain further insight into the chemistry, microstructure, failure mechanisms and engineering properties of UHPCM nanocomposites. Scanning electron microscopy (SEM) was performed using ultra-high resolution JEOL 7500F with a cold field emission emitter on hydrated cement pastes after 7 days of curing (as described above). The specimens were first coated with osmium using a sputter coater (DESK II), and then imaged in high-vacuum mode at an accelerating voltage of $10 \mathrm{kV}$. Transmission electron microscopy (TEM) was performed using a JEM-2200FS field emission transmission electron microscope, equipped with a 200 $\mathrm{kV}$ field emission gun (FEG) and the in-column energy filter (Omega filter) that allows a zero-loss image. Fourier transform infrared spectroscopy (FTIR) and Raman spectroscopy were used to validate the functionalization of the CBNs. Transmission FTIR spectra were collected with a Nicolet Magna-560 FTIR spectrometer equipped with a MCT (Mercury Cadmium Telluride) detector. The test procedures used to determine the engineering properties of CBN incorporated UHPCM and control UHPCM were as follows: Compression test was performed using a test frame (MTS Systems Corp.) at a constant displacement rate of $0.625 \mathrm{~mm} / \mathrm{min}$. Samples were $50 \mathrm{~mm}$ cube specimens according to ASTM C109 [67] and were tested at 7 days of cure. Six samples were tested and the average value is reported. Flexure test was performed using a deflection controlled Instron test system with a load capacity $89 \mathrm{KN}$. Sample dimensions were $12.5 \times 50 \times 150 \mathrm{~mm}$ and centerpoint loading was applied on a span of $125 \mathrm{~mm}$ with a displacement of $0.012 \mathrm{~mm} / \mathrm{min}$ following ASTM C348 [68]. Six samples were tested at 7 days of cure. Load and deflection data were collected using a data acquisition system (National Instruments). Energy Absorption Capacity was calculated from the area under the load-deflection curve. In some cases, this is also called flexural toughness [69]. Abrasion tests were conducted on cylindrical specimens (cured for 7 days) of dimension $100 \mathrm{~mm}$ diameter and $50 \mathrm{~mm}$ height, following ASTM C944 [70]. The cylindrical surfaces of the specimens were kept under the abrasion device and subjected to abrasion for $2 \mathrm{~min}$. At the end of each 2-min abrasion period, the test specimen was removed from the device and cleaned with blowing air to remove any debris on the abraded surface. Six specimens were tested and the mass loss due to abrasion was recorded. Moisture absorption rate tests were performed on cylindrical specimens of $100 \mathrm{~mm}$ diameter and $100 \mathrm{~mm}$ height following ASTM C1585 [71]. The sides and top surfaces of specimens were covered with impermeable adhesive sheets, and the bottom surface was immersed (1-3 mm depth) in water. The mass gain of the specimen (due to capillary sorption) was measured frequently (with the wet surfaces patted dry prior to weight measurement).

\section{Experimental result and discussion}

\subsection{Characterization of carbon nanomaterials after acid oxidation}

\subsubsection{FTIR spectroscopy}

FTIR offers low detection limit and high sensitivity for CBN characterization. Thus, FTIR spectrometer in transmission mode, equipped with a sensitive MCT detector was used to investigate the relatively low concentration of functional groups introduced after acid oxidation of CNTs and CNFs. Figure 1 presents FTIR spectra for two types of MWNTs (MWNT-A and MWNT-B) and CNF before and after acid oxidation. Figure $1 \mathrm{a}$ and $\mathrm{b}$ present the transmission FTIR spectra of a MWNT before and after acid oxidation. Like graphite, pristine CNTs have featureless FTIR spectra with extremely low infrared absorption intensities. After acid-oxidation, two new bands appear at 1715 and 1160 $\mathrm{cm}^{-1}$, which are attributed to the $\mathrm{C}=\mathrm{O}$ and $\mathrm{C}-\mathrm{O}$ stretching vibrations, respectively, of the carboxylic group $(-\mathrm{COOH})$. Peaks at 1635 and $1560 \mathrm{~cm}^{-1}$ are due to $C=C$ stretching. The intense, broad line centered at $3422 \mathrm{~cm}^{-1}$ is associated with the $-\mathrm{OH}$ stretching mode of the $-\mathrm{COOH}$ group. The increase in relative intensities of bands at 1068 and 3420 $\mathrm{cm}^{-1}$ suggests a rise in $-\mathrm{OH}$ groups on nanotube surfaces after acid-oxidation. Similar trends are observed in the case of acid-functionalized CNF (Fig. 1c). FTIR spectroscopy indicates that treatment with the strong oxidizing acid led to formation of oxygen-containing groups (such as carboxylic and hydroxyl) on the CNT and CNF surfaces.

\subsection{Characterization of carbon nanomaterials after fluorination and ethyl carboxylation}

\subsubsection{Raman spectroscopy}

The Raman spectroscopy was carried out for both types of MWNTs (MWNT-A and B) before and after fluorination. The two main bands typically present in the Raman spectrum of MWCNTs [72] were observed in MWNTs before fluorination: the band at $1580 \mathrm{~cm}^{-1}$ is assigned to the $G$ mode; and band around $\sim 1300 \mathrm{~cm}^{-1}$ is assigned to the $D$ mode, which is often referred to as the disorder band. The $\mathrm{G}$ mode or (TM-Tangential Mode), located around 1580 $\mathrm{cm}^{-1}$, is assigned to the in-plane vibration of the $\mathrm{C}-\mathrm{C}$ bond, while the $D$ mode results from the breathing mode of carbon hexagons. The results presented for MWNT-A (in Fig. 2a) show that, after fluorination, there are small 


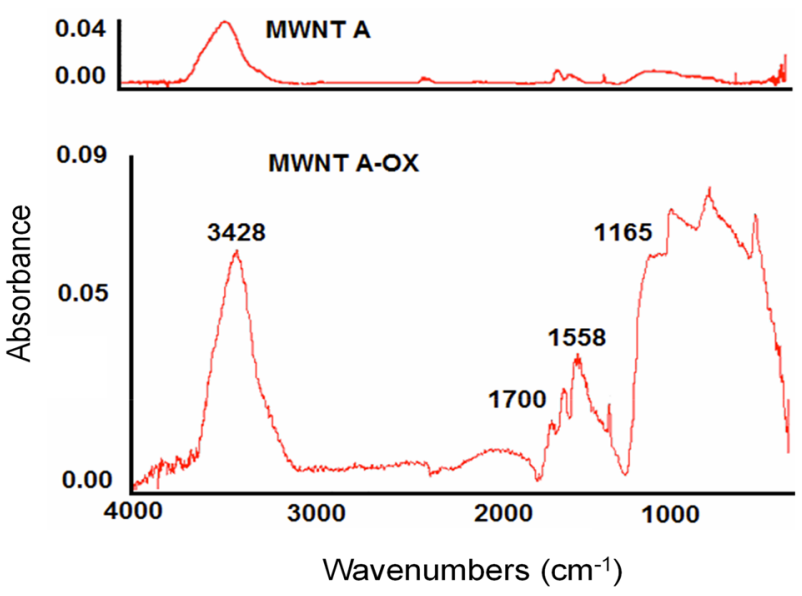

(a) MWNT A before and after acid-oxidation.
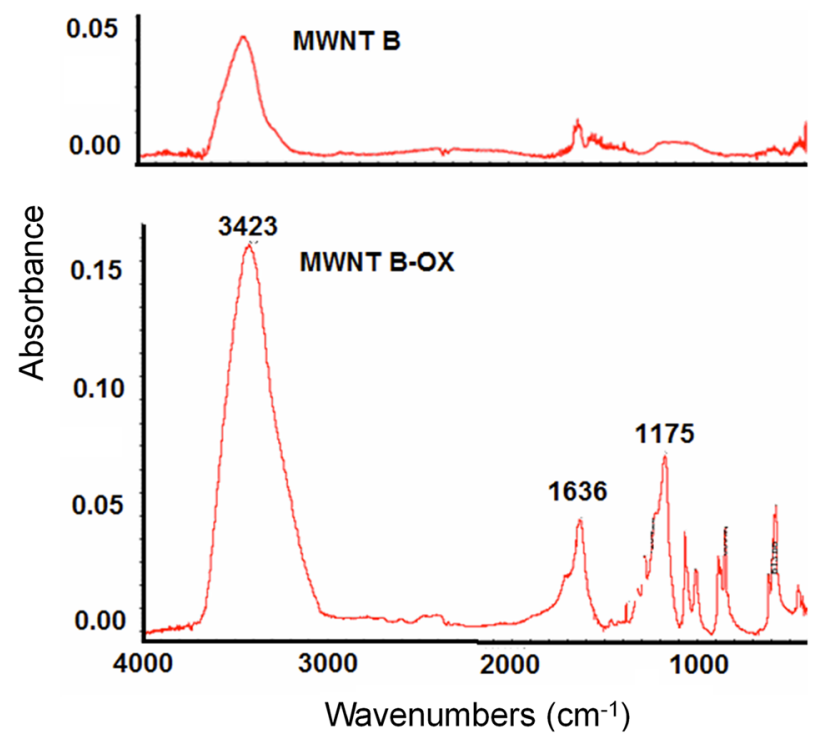

(b) MWNT B before and after acid-oxidation.

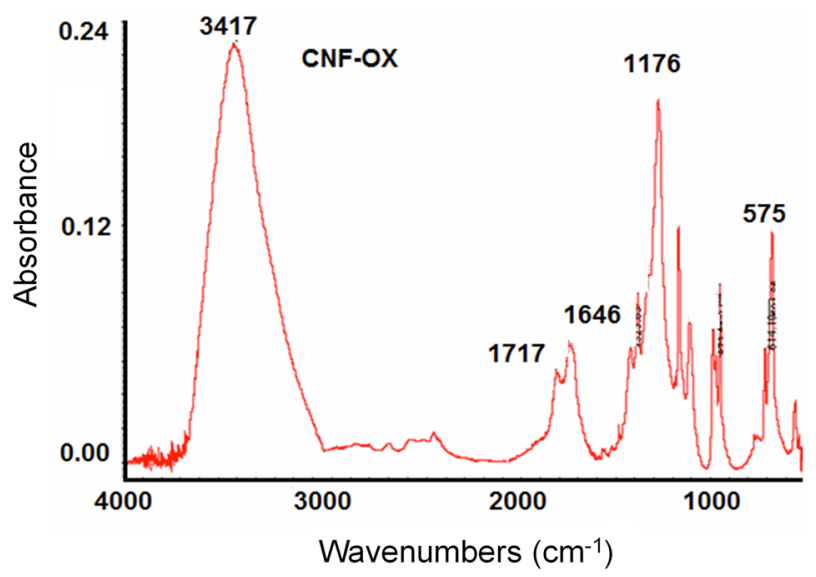

(c) Acid-oxidized CNF.

Fig. 1 FTIR spectra of pristine and acid-oxidized CNT and CNF

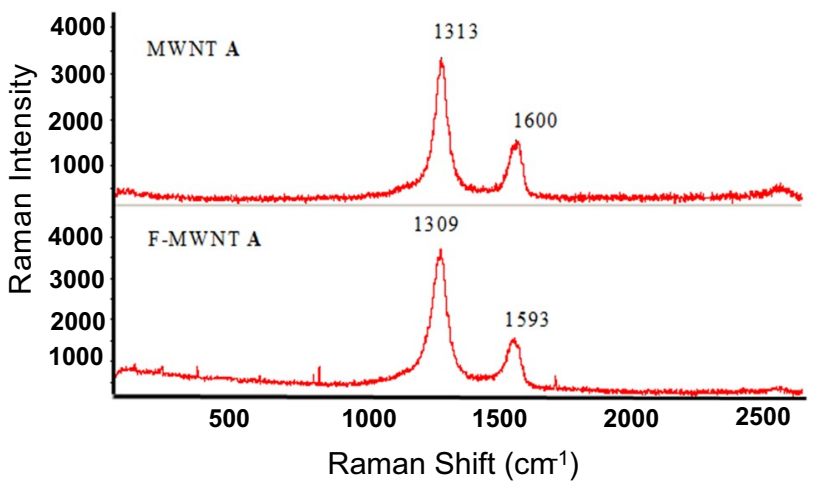

(a)

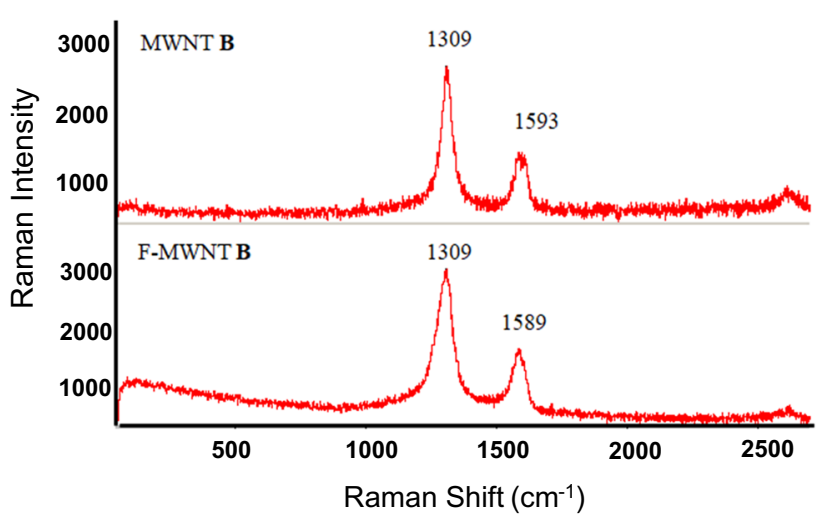

(b)

Fig. 2 Raman spectra for MWNT A and B before and after fluorination

shifts to lower energy in the positions of both $D(\sim 1300$ $\mathrm{cm}^{-1}$ ) and $\mathrm{G}$ (near $1600 \mathrm{~cm}^{-1}$ ) peaks. This is presumably due to the fluorine groups attached to the nanotube sidewalls. There also appears to be a small increase in the width of the $D$ peak; from a full width at half maximum (FWHM) of ca $63 \mathrm{~cm}^{-1}$ in the un-fluorinated sample to 69 $\mathrm{cm}^{-1}$ in the fluorinated sample. MWNT-B (Fig. 2b) shows a $4 \mathrm{~cm}^{-1}$ downshift of only the $G$ peak, but does show significantly larger broadening of the $D$ peak, from a FWHM value of $54 \mathrm{~cm}^{-1}$ in the un-fluorinated sample to $81 \mathrm{~cm}^{-1}$ in the fluorinated sample. The increase in peak width suggests that fluorination results in more substitution into the rings and more ring opening for the $B$ sample than for the A sample.

\subsubsection{FTIR spectroscopy}

The FTIR spectra for MWNTs (MWNT-A and MWNT-B) before and after fluorination and subsequent ethyl carboxylation are presented in Figs. 3 and 4. After fluorination, the appearance of $\mathrm{C}=\mathrm{C}$ and $\mathrm{C}-\mathrm{F}$ bonds confirms the success 


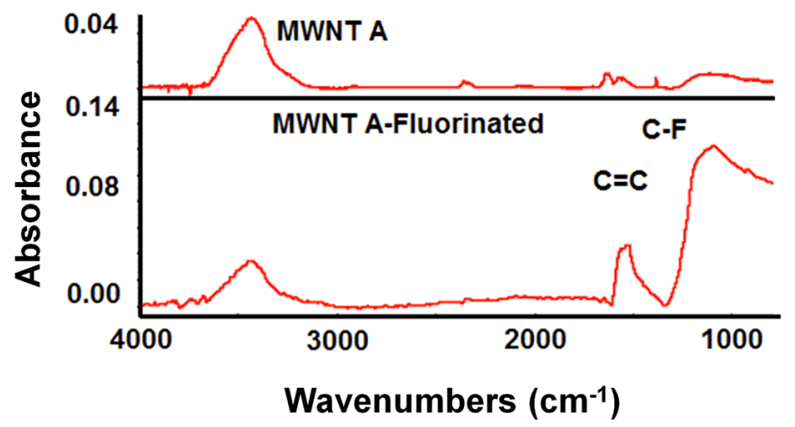

(a)

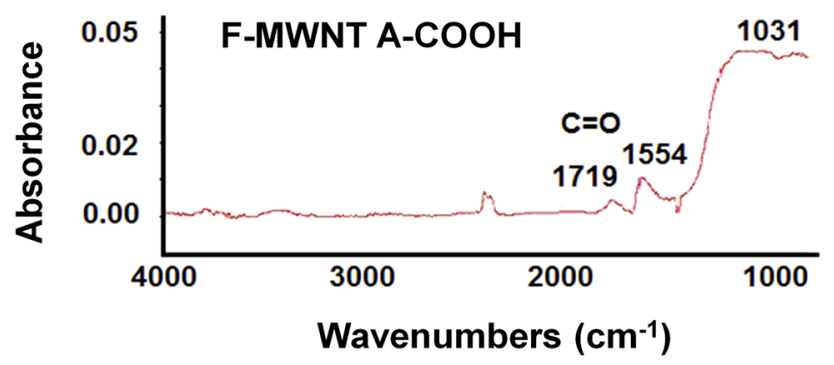

(b)

Fig. 3 FTIR spectra for MWNTs, MWNT A a before and after fluorination and $\mathbf{b}$ after ethyl carboxylation

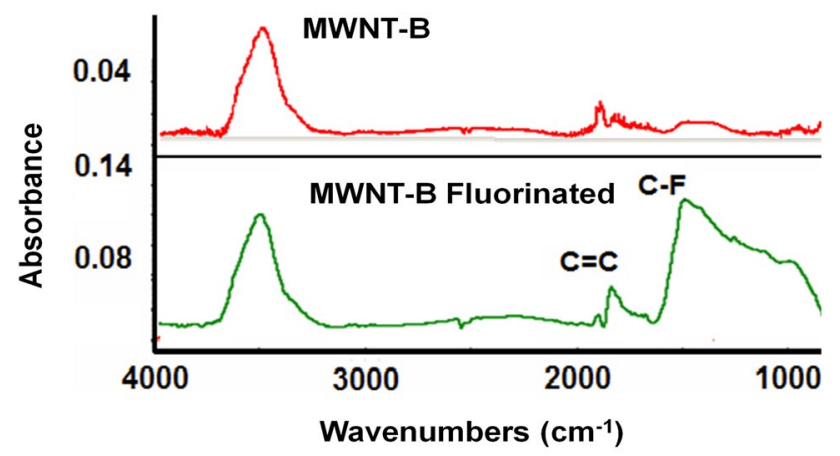

(a)

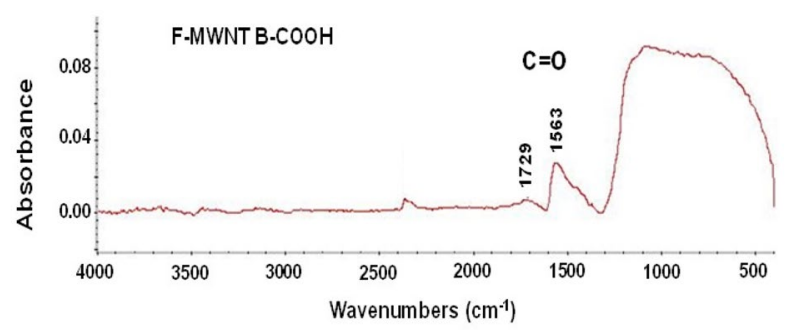

(b)

Fig. 4 FTIR spectra for MWNTs, MWNT B a before and after fluorination and $\mathbf{b}$ after ethyl carboxylation of fluorination. After ethyl carboxylation, a new peak was observed at $\sim 1700 \mathrm{~cm}^{-1}$ confirming carboxylation.

\subsection{Engineering properties of cementitious nanocomposites}

Surface functionalization of CBNs followed by their uniform dispersion in UHPCM demonstrated gains in different engineering properties. Figures 5, 6, 7, 8, 9 present flexural performance (Figs. 5 and 6), compressive strength (Fig. 7), abrasion resistance (Fig. 8), and moisture sorption rate (Fig. 9) of UHPCM with the introduction of $0.03 w t . \%$ CBNs.

\subsubsection{Flexural Strength}

Figure 5 presents typical flexural load-deflection behavior for UHPCM (control) and UHPCM with the introduction of $0.03 \mathrm{wt} . \%$ (weight fractions of dry cementitious materials) of CBNs. Carboxylic acid functionalized multi-walled carbon nanotubes (MWNT-B-OX) at $0.03 \mathrm{wt}$.\% has the highest gain in flexural strength, deflection and energy absorption capacity (area underneath the load-deflection curve).

Acid oxidized carbon nanotube (MWNT-B) at 0.03 wt.\% yielded: $30 \%$ increase in flexural strength; $>100 \%$ increase in energy absorption capacity; and $>200 \%$ increase in deflection of the UHPCM compared to that of plain UHPCM (without any reinforcement) (Fig. 6). The FTIR spectrum (Fig. 1b) of MWNT-B shows a higher amplitude for the $\mathrm{OH}$ peak $\left(\sim 3428 \mathrm{~cm}^{-1}\right)$ after acid oxidation compared to that of MWNT-A (Fig. 1a). This confirms that MWNT-B has higher density of $\mathrm{COOH}$ group on the MWNT walls compared to that of MWNT-A. Higher density of $\mathrm{COOH}$ functional groups also makes the nanotube surfaces more hydrophilic, and thus benefits their dispersion in aqueous media. Hydrated cement is comprised primarily of calcium silicate hydrate and calcium hydroxide. Under basic conditions, $\mathrm{COOH}$ functionalities on the MWNT will convert to $\mathrm{COO}^{-}$groups, which will have strong ionic interactions with the $\mathrm{Ca}^{2+}$ ions in cement hydrates. Previous FTIR [38] studies suggested possible chemical bond formation between carboxylated MWNT and cement matrix. These different kinds of bonding and strong interactions increase the load transfer efficiency at the interface. With high interfacial interactions, CNTs can provide a better and stronger interface for stress transfer and delay microcrack propagation [8]. This explanation is consistent with the highest gain in energy absorption and ductility being observed for acid oxidized carbon nanotubes MWNT-B compared to other CBNs. Similar gains in flexural strengths were observed by Li et. al [38] and Konsta-Gdoutos et. al [16] when using MWNTs as reinforcing agents, however the weight fractions used were 16 times and 1.6 higher than those of the current study. Similarly, a recent study 
Fig. 5 Typical flexural loaddeflection behavior of UHPCM (plain matrix) and 0.03 wt.\% of CBNs: MWNT-A-OX and MWNTB-OX are acid oxidized MWNTs; F-MWNT-A-COOH is MWNT-A fluorination followed by ethyl carboxylation; CNF-OX is acid oxidized CNF; and MWNT-B and MWNT-A are non-functionalized MWNTs
- UHPCM
- 0.03 wt \% MWNT-B-OX
× 0.03 wt \% F-MWNT-A-COOH
- 0.03 wt \% MWNT-A-OX

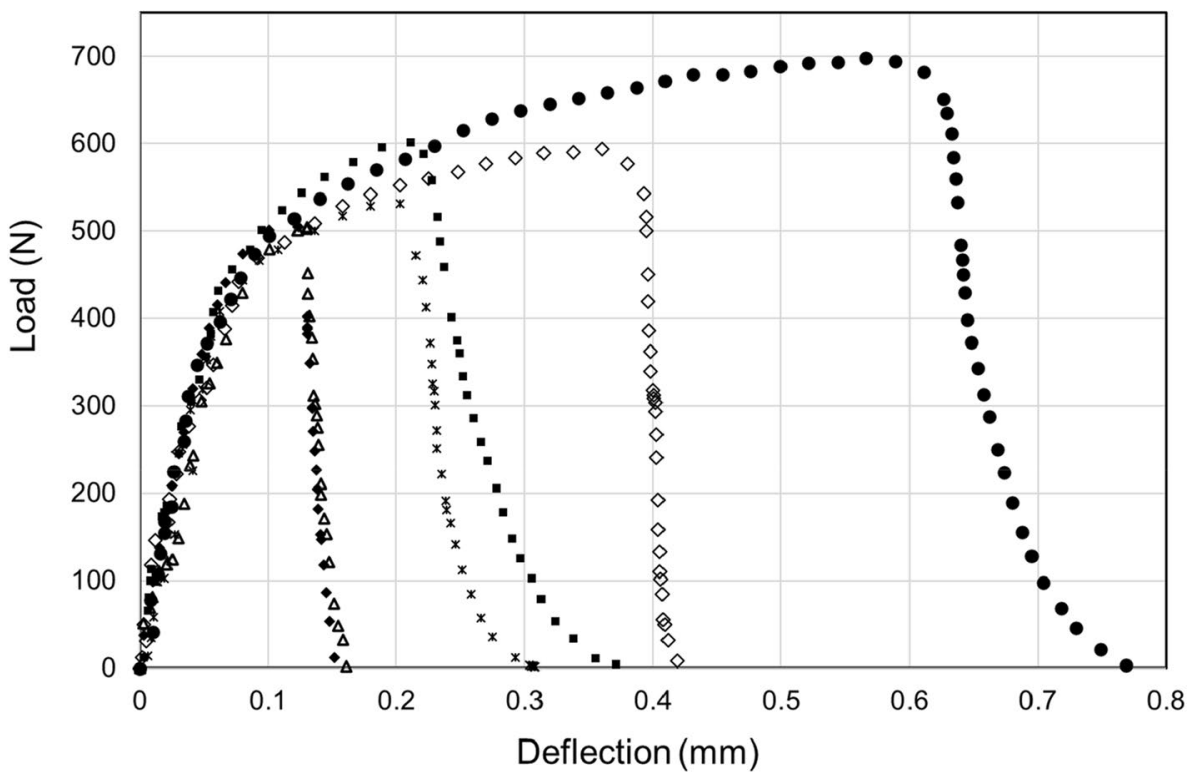

incorporating 0.04 wt.\% MWNT showed $21.7 \%$ increase in flexural strength at 28 days of curing [59].

Fluorination followed by ethyl carboxylation for MWNTA showed 15\% higher flexural strength compared to that of MWNT-B (Fig. 6a). This was confirmed by XPS (X-Ray Photoelectron Spectroscopy) data after ethyl carboxylation for MWNT-A (F-MWNT-A-COOH) had $6.1 \% \mathrm{O}_{1 \mathrm{~s}}$ compared to MWNT-B (F-MWNT-B-COOH) had only $4.4 \%$ of $\mathrm{O}_{1 \mathrm{~s}}$ (Supporting Data, Table S-1). However, functionalization of carbon nanotubes via fluorination and subsequent ethyl carboxylation, led to smaller improvements in UHPCM performance. It is possible that this could be due to the lower density of functional groups in the fluorinated samples, although the differences in intensity of the $\mathrm{C}=\mathrm{O}$ stretch in the FTIR (and so in carboxylate concentration) are modest. Another notable observation was that when non-functionalized carbon nanotubes, MWNT-A, were introduced to UHPCM, there was no change in flexural performance and energy absorption. Addition of non-functionalized CNT, MWNT-B, however, lowered the flexural strength (Fig. 6a) and energy absorption (Fig. 6b). This may be due to the smaller outer diameter (20-40 nm) of MWNT-A which would likely reduce the number of fine pores of the UHPC and increase the strength. This probably reduces capillary stress and improves early strain capacity of the nanocomposites [73]. This could also be due to surface area effect, smaller diameter at a given weight fraction means larger interfacial area and hence greater interfacial interactions.
Addition of CNF-OX showed a $14 \%$ gain in flexural strength and this is lower compared to flexural strength gain for addition of MWNT-B-OX (Fig. 6a). This could be due to the lower tensile strength and elastic modulus of nanofibers compared to those of carbon nanotubes. In addition, lower specific surface area of CNF-OX will lower the interfacial interactions of CNF-OX with the cement matrix compared to MWNT-B-OX and hence have a lower gain in flexural strength. The improvements in energy absorption capacity and deflection were $67 \%$ (Fig. 6b) and $150 \%$ (Fig. $6 \mathrm{C}$ ) respectively for addition of CNF-OX. The gain in deflection and energy absorption capacity for CNFOX were higher than MWNT-A-OX. This could be due to the relatively large length of CNF which would be expected to improve ductility and energy absorption capacity via nano crack bridging. Past studies also showed CNF is effective in improving the fracture properties of the cement matrix, by controlling nano cracks of the matrix, this also improves the early age strain capacity [42]. This could also be due to better interfacial interactions of CNF-OX with cement matrix compared to that of MWNT-A-OX. It is also mentioned in the literature that CNF diameters are close in dimensions to the thickness of the calcium silicate hydrate in hydrated cement and expected to have different bonding mechanisms [74]. A previous study on CNF reinforcement in cement paste using polycarboxylate-based high range water reducer dispersing agent resulted in 35\% and $65 \%$ increases in flexural strength but the weight fractions 
Fig. 6 Flexural performance for UHPCM reinforced with CBNs at 0.03 wt.\%: a. flexural strength; b. energy absorption capacity; and c. deflection.

Error bars shown are standard deviations determined from 6 replicate samples

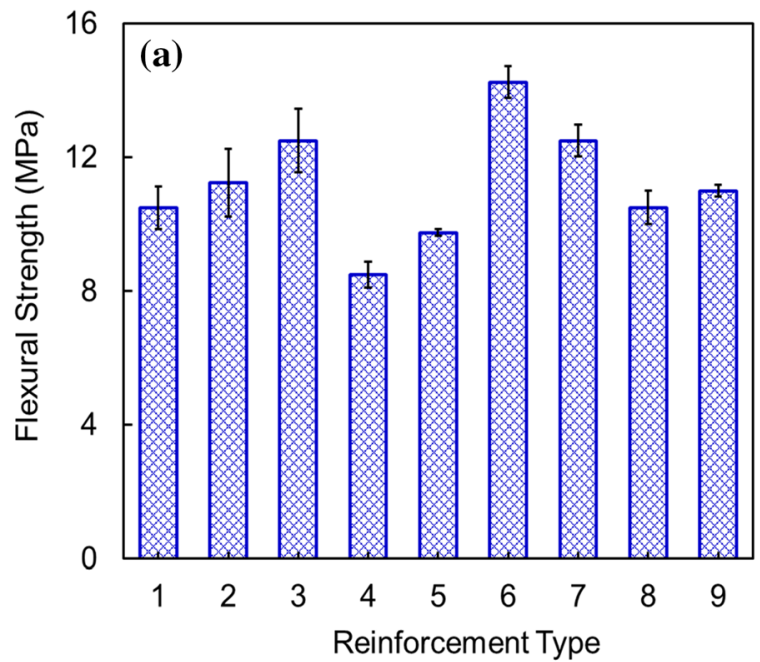

1. MWNT-A

2. F-MWNT-ACOOH

3. MWNT-A-OX

4. MWNT-B

5. F-MWNT-B COOH

6. MWNT-B-OX

7. CNF-OX

8. Nanoplatelets

9. UHPCM
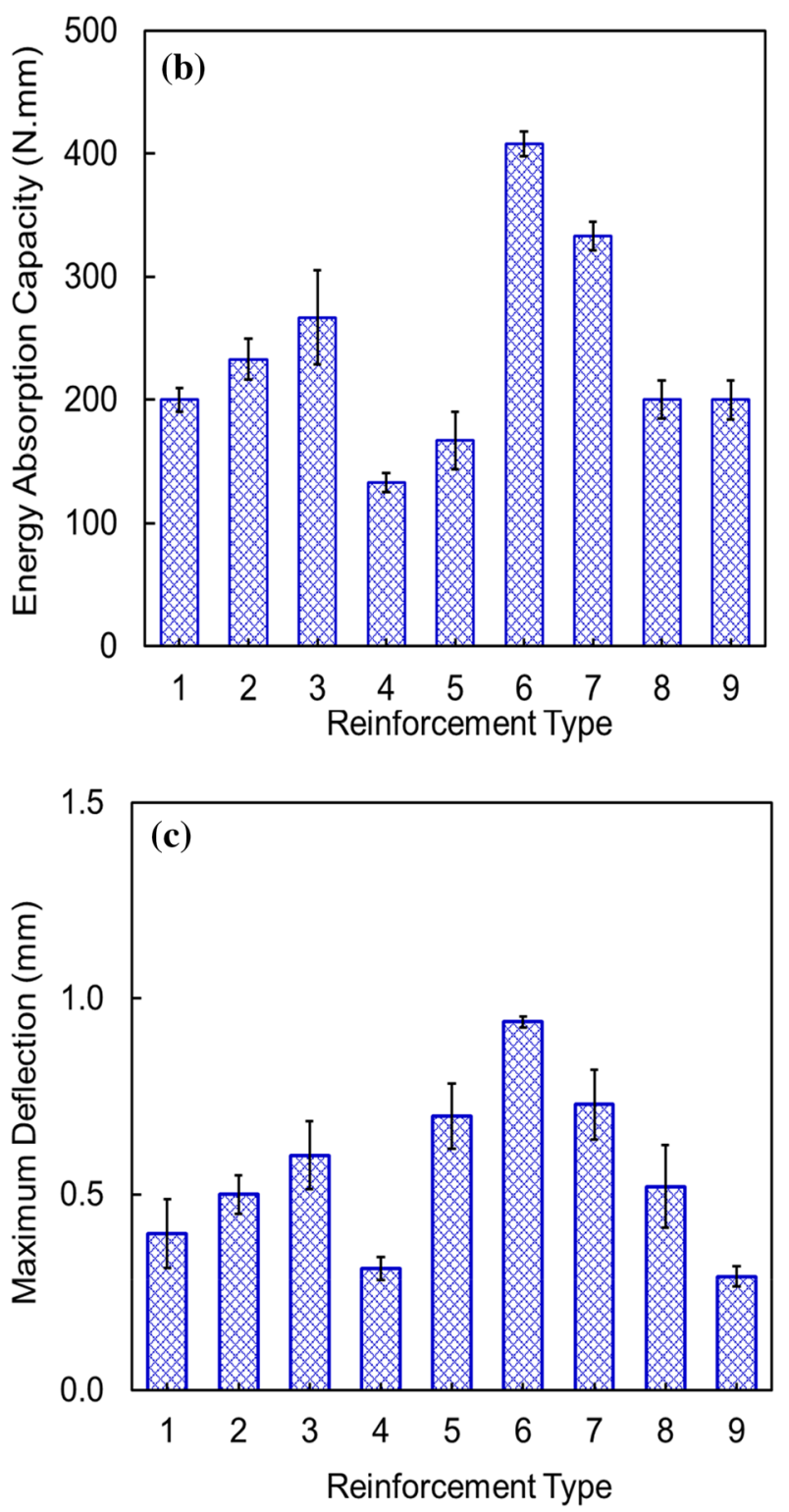

1. MWNT-A

2. F-MWNT-ACOOH

3. MWNT-A-OX

4. MWNT-B

5. F-MWNT-B $\mathrm{COOH}$

6. MWNT-B-OX

7. CNF-OX

8. Nanoplatelets

9. UHPCM

1. MWNT-A

2. F-MWNT-ACOOH

3. MWNT-A-OX

4. MWNT-B

5. F-MWNT-B $\mathrm{COOH}$

6. MWNT-B-OX

7. CNF-OX

8. Nanoplatelets

9. UHPCM 
Fig. 7 Compressive strength for UHPCM reinforced with carbon-based nanomaterials at 0.03 wt.\%. Error bars shown are standard deviations determined from 6 replicate samples
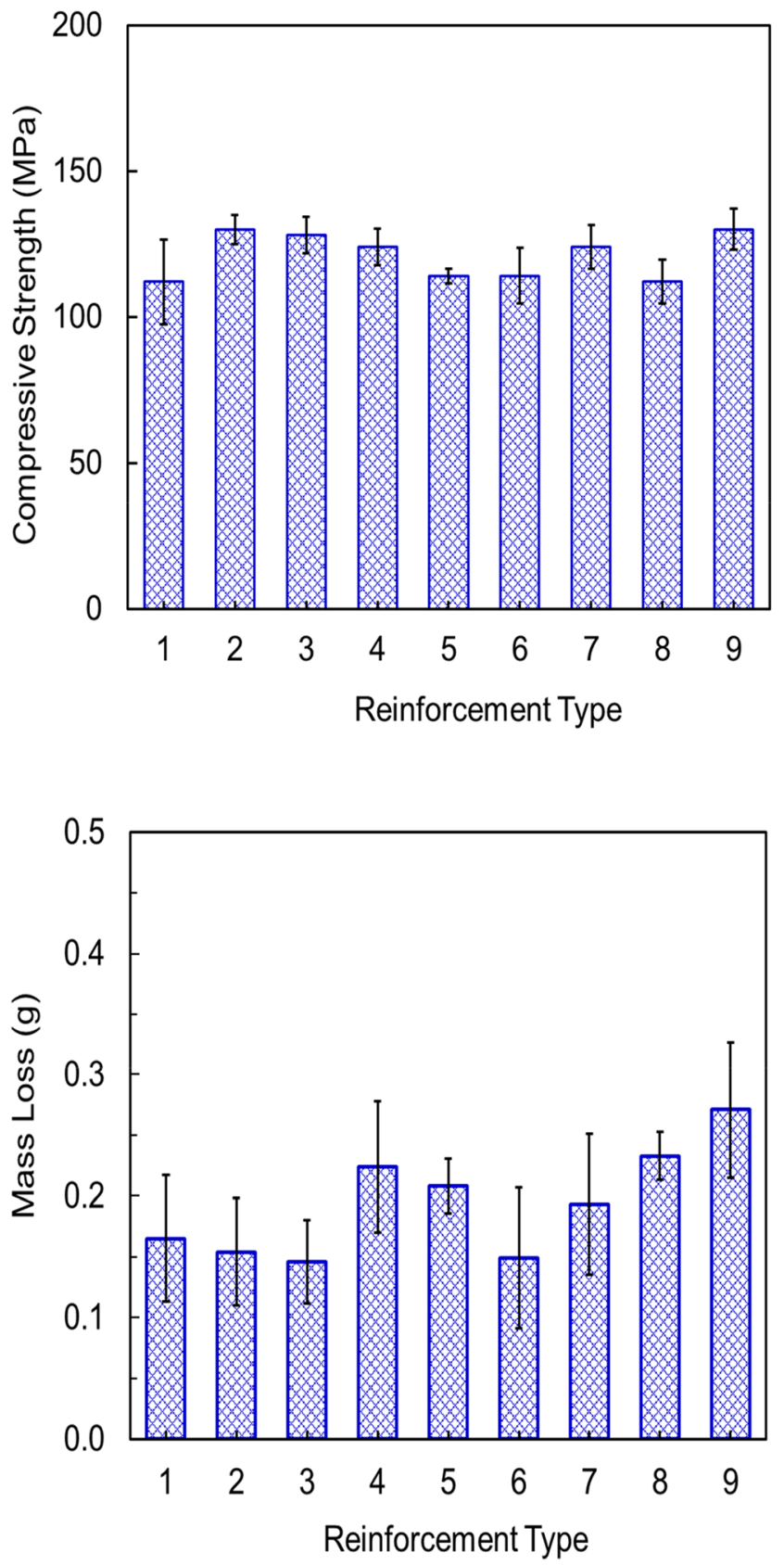

1. MWNT-A

2. F-MWNT-ACOOH

3. MWNT-A-OX

4. MWNT-B

5. F-MWNT-B $\mathrm{COOH}$

6. MWNT-B-OX

7. CNF-OX

8. Nanoplatelets

9. UHPCM
Fig. 8 Abrasion resistance for UHPCM reinforced with carbon-based nanomaterials at 0.03 wt.\%. Error bars shown are standard deviations determined from 6 replicate samples are 16 times and 33 times higher than the current study [56].

Addition of GNP has no effect on flexural strength (Fig. 5a), this might be the results of less functionalization, or functionalization predominantly at the edges of the nanoplatelets giving less effective bonding to the cement matrix. This could also be because the weight fractions are not high enough to significantly increase the flexural strength. In addition, the tensile strength of GNP may affect the ultimate mechanical performance of the nano-reinforced cement matrix, as the GNP used in the current study was much lower in tensile strength compared to previous reported studies [75]. A few past studies demonstrated increases in flexural strength using GNP however, the weight fractions are twice that of the current study [76, 77]. Though there is no improvement in flexural strength and energy absorption capacity, increase in deflection was observed with GNP (Fig. 6c). This could be due to GNP having some reinforcing benefits to the matrix, which is reflected through enhanced ductility. Increases in flexural toughness and modulus are reported in past studies incorporating GNP in cement matrices [78]. 
Fig. 9 Moisture sorption rate for UHPCM reinforced with carbon-based nanomaterials at 0.03 wt.\%. Error bars shown are standard deviations determined from 6 replicate samples

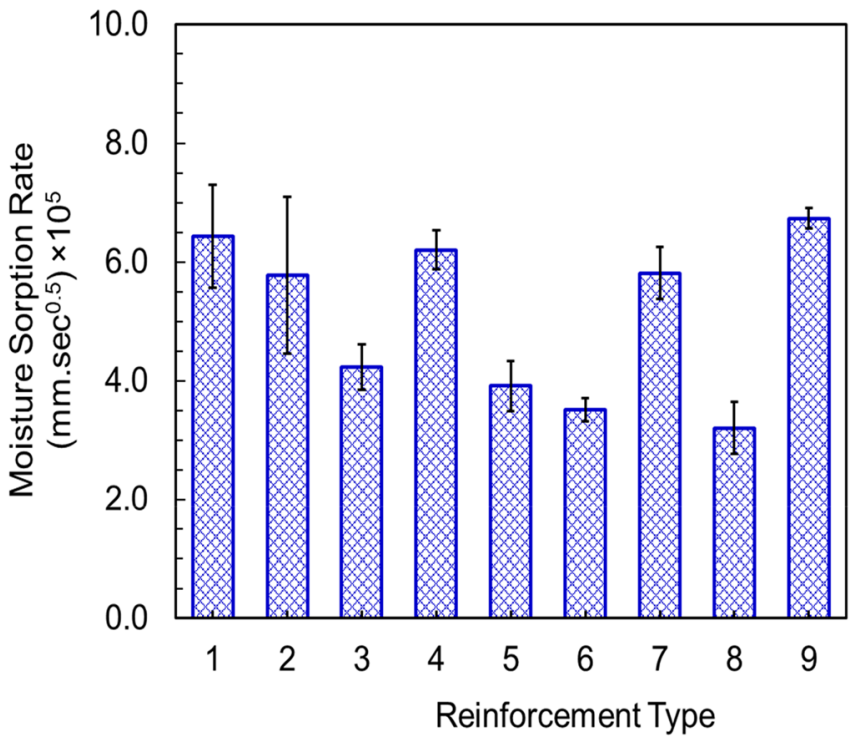

1. MWNT-A

2. F-MWNT-ACOOH

3. MWNT-A-OX

4. MWNT-B

5. F-MWNT-B $\mathrm{COOH}$

6. MWNT-B-OX

7. CNF-OX

8. Nanoplatelets

9. UHPCM
Various toughening mechanisms: crack deflection; crack bridging; and cracking branching are also observed with uniformly dispersed GNPs $[79,80]$. The SEM image below (Fig. 14) shows GNPs around micro cracks, possibly providing resistance to crack propagation.

In the past, a few attempts have been made to lower the dosage of $\mathrm{CBNs}$ as reinforcing agents in cementitious matrices: MWNT as low as 0.03 wt.\% [39]; and CNF as low as $0.025 \mathrm{wt} . \%$ [42]. Mohsen et al. [39] tried to determine the optimum weight fraction of MWNT in cementitious composites by using different weight fractions (by weight of cement): $0.03 \% ; 0.08 \% ; 0.15 \% ; 0.25 \% ; 0.35 \%$; and $0.5 \%$. The maximum flexural strength was achieved at 0.25 wt.\% and no significant increase in flexural strength was observed at 0.03 wt.\%. Metaxa et al. [42] studied the reinforcement effects of non-functionalized CNF in cementitious matrices at weight fractions ranging from 0.025 to $0.1 \%$ and reported the highest gain in flexural strength was achieved at $0.048 \mathrm{wt} . \%$.

\subsubsection{Compressive strength}

Though significant improvement in flexural strength of UHPCM was observed with the introduction of acid functionalized CNT, the corresponding effects of CNTs on compressive strength were not statistically significant (Fig. 7). Flexural strength of UHPCM largely accounts for tensile mode of failure and indirect measure tensile strength of cement composites [81]. Carbon nanotubes are known for its superior tensile strength, MWNTs have a tensile strength of $63 \mathrm{GPa}$, which is approximately 50 times greater than steel $[14,82]$. Generally, CNTs are not nearly as strong under compression [83]. Because of their hollow thin-walled structure and high aspect ratio, they are highly susceptible to buckling when loaded in axial compression [84-86]. In addition, during compression CNTs are in the compressive state because of the transverse expansion and cracking and could not play a bridging role in the crack, whereas during flexure CNTs can play a vital role in crack bridging (Fig. 11a-c), strengthening the crack and increasing the flexural strength. Thus, addition of CNTs would not be expected to increase the compressive strength of UHPCM. However, some past studies have shown increases in compressive strength with the introduction of CNTs but their weight fractions are much higher, ranging from $0.5 \mathrm{wt} . \%$ to $2.0 \mathrm{wt} . \%$. [32, 34, 38, 87]. Other studies showed decreases in compressive strength with the addition of CNTs [55]. It is very difficult to make a direct comparison with past findings versus the results of this work because there are differences in: manufacturing methods of CNTs that will significantly influence the ultimate properties; dimensions of CNTs; surface treatment methods; and cement matrices (mostly past studies cover general purpose cement paste, mortar and concrete made with general purpose cement).

\subsubsection{Abrasion resistance}

Abrasion resistance is one of the key considerations for long term durability of concrete. Owing to their unique properties, CBNs can be very attractive in improving abrasion resistance in cementitious composites [88]. Abrasion resistance was estimated through mass loss after abrading cement paste samples following ASTM C944. The lower the mass loss the higher the abrasion resistance. Both acid oxidized CNTs, MWNT-A and MWNT-B at 0.03 wt.\% demonstrated the highest abrasion resistance, and improvements are $\sim 45 \%$ compared to that of plain cement paste (Fig. 8). 
Improving abrasion resistance is most likely attributable to surface effects and density of surface functional groups. Acid oxidized MWNT-B has the higher density of $\mathrm{COOH}$ functional groups and thus has better interfacial interactions with cement matrix. Though GNP has higher specific surface area, CNF have better interfacial interactions with cement matrix due to surface functionalization. Improvements in abrasion resistance can also be explained by the crack arresting and crack thinning effect of CNTs [38] and CNFs [42]. SEM images further confirmed micro crack bridging of CNT and CNF vide infra, Figs. 11-13. However, most past research on improvement of abrasion resistance of cement composites used nanoparticles [89-91], micro fibers $[92,93]$ or polymer impregnations [94].

\subsubsection{Moisture absorption rate}

Graphene nanoplatelets (GNPs) were introduced in nonfunctionalized form into the UHPCM at $0.03 \mathrm{wt} . \%$ with the primary objective of improving the moisture barrier properties by forcing a tortuous diffusion path (Fig. 9). The introduction of $0.03 \mathrm{wt} . \%$ GNP into the cement matrix lowered the moisture sorption rate of UHPCM by more than $50 \%$. This is consistent with the suggestion that the layered structure of GNP can create a tortuous path in the cement matrix that effectively lowers the moisture penetration
[95]. In addition, presence of GNPs can improve the microstructure of the cement matrix by reducing porosity and promoting the formation of crystalline calcium hydroxide early in the aging process $[96,97]$.These may benefit impermeability in GNP-reinforced cement composites. Previous studies from our group have shown that uniformly dispersed graphite nanoplatelets can enhance barrier qualities in cementitious matrices [5]. The findings of Du and Pang [98] further support the current findings, from their studies with GNP-reinforced ( 2.5 wt.\%) cement mortar exhibited significant enhancements in moisture barrier properties. A recent study indicated that a combination of graphene oxide (GO) and CNTs can significantly reduce the water permeability of cementitious composites due to simultaneous bridging effect of CNTs and the nucleation effect of GO [99].

\subsection{Microscopic characterization}

A TEM image of the multi-walled carbon nanotubes, MWNT-B after acid-oxidation followed by introduction into UHPCM is shown in Fig. 10a. The TEM image shows (Fig. 10a) the presence of nucleated cement hydrates on the functionalized nanotube surfaces confirming the strong interactions of cement hydrates with CNT walls. SEM images (Fig. 10b-c) of the fractured surface of
Fig. 10 TEM image $\mathbf{a}$ and SEM images b-c of the fractured surface of a UHPCM with 0.03 wt.\% of acid-functionalized MWNT-B
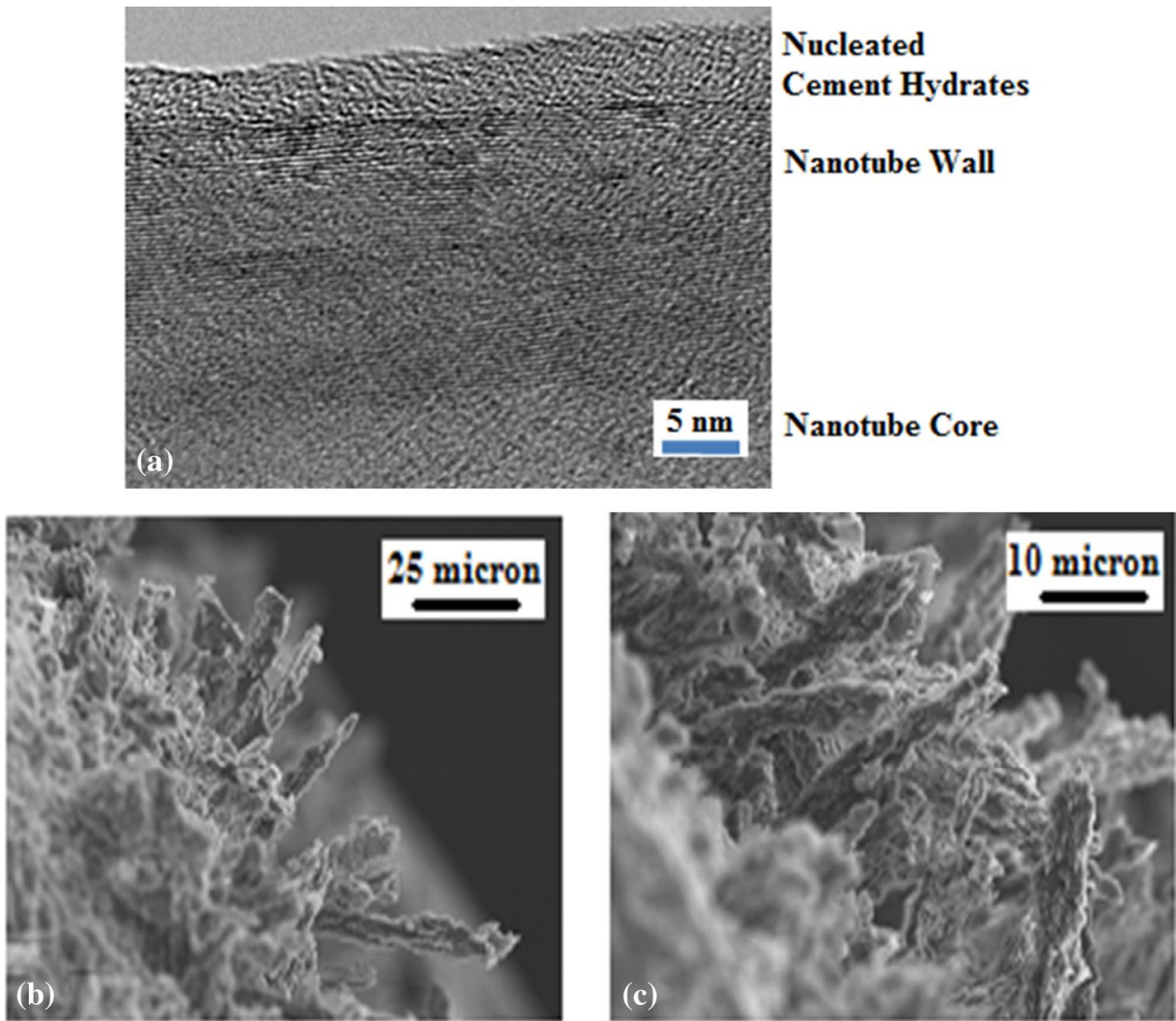

SN Applied Sciences A SPRINGER NATURE journa 

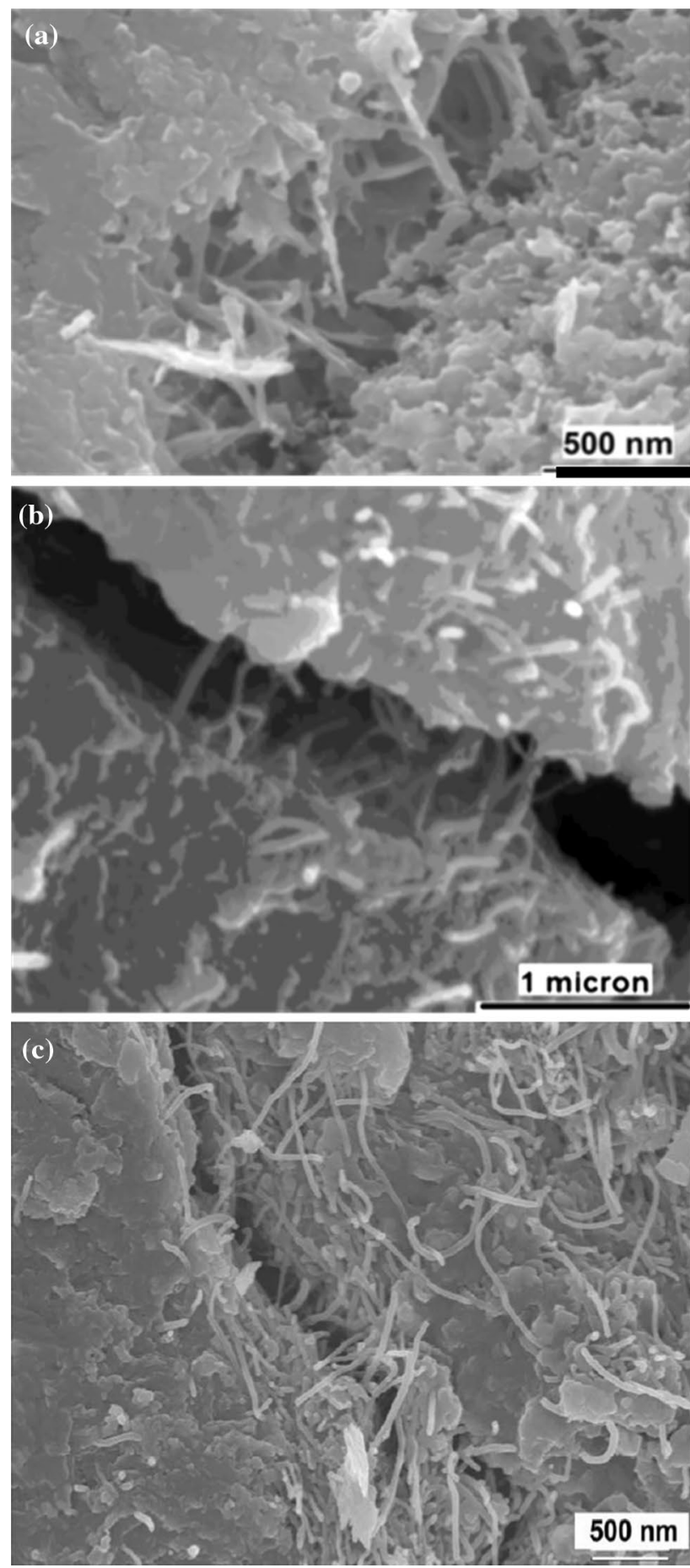

Fig. 11 SEM images showing bridging of micro-cracks by acidfunctionalized MWNT-B in UHPCM at $0.03 \mathrm{wt} . \%$

UHPCM with 0.03 wt.\% of acid-oxidized MWNT-B shows the pull-out of CNTs and these CNTs are uniformly coated with cement hydration products. This indicates the compatibility of $\mathrm{COOH}$ functionalized CNT surfaces with the cement hydrates which benefits strong interfacial interactions of CNTs with the cement matrix. This explains
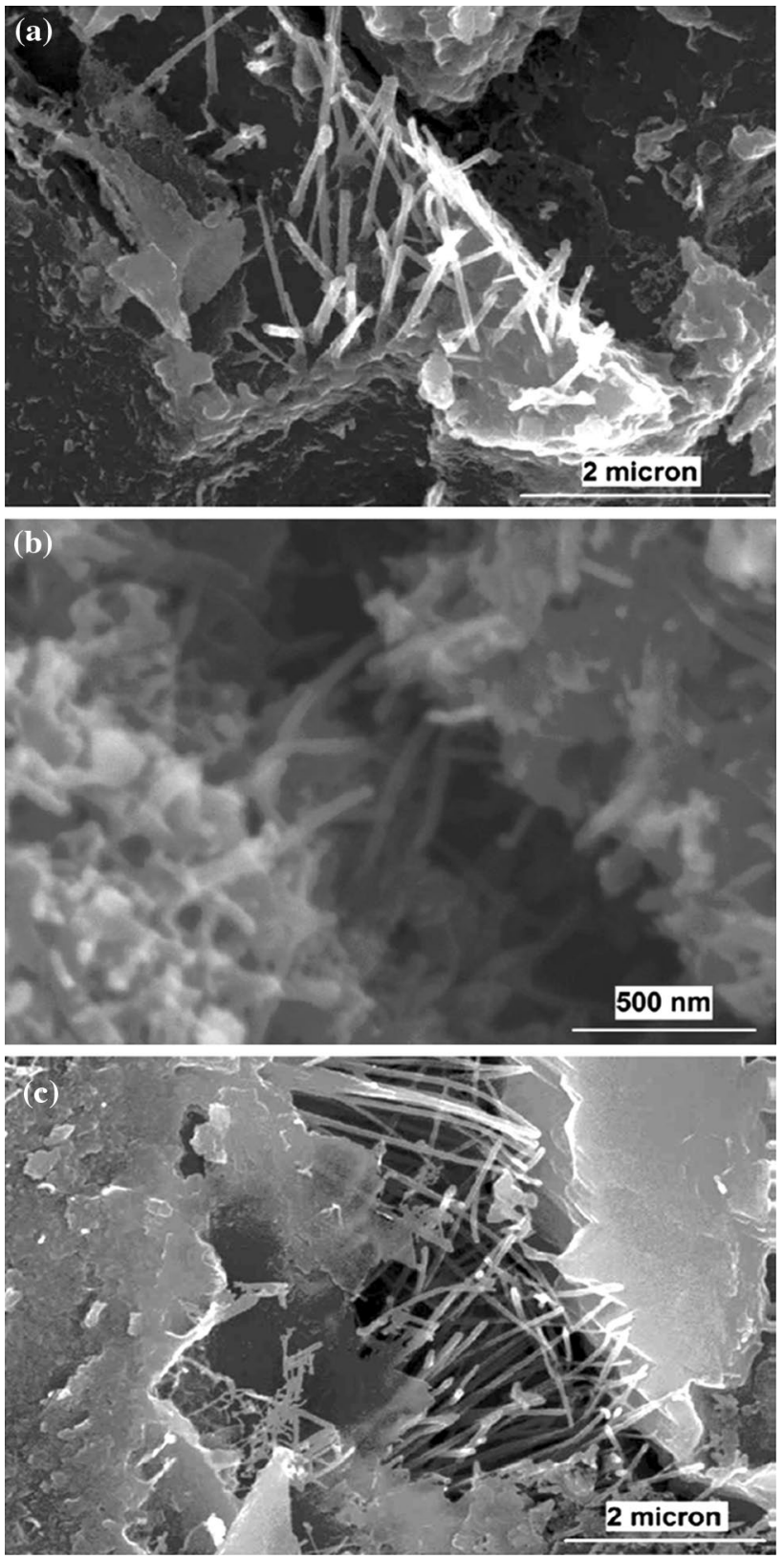

Fig. 12 SEM images of UHPCM reinforced with 0.03 wt.\% CNF-OX, showing nano-crack thinning $\mathbf{a}$ and nano-crack bridging by CNF bc

the increase in flexural strength with the introduction of MWNT-B-OX. Debonding seems to have taken place away from the actual interface within the matrix, which points at the adequately strong bond developed between the functionalized CNTs and the cementitious matrix. The SEM images of Fig. $10 \mathrm{~b}$ and $\mathrm{c}$ also provide evidence for the uniform dispersion of acid-functionalized CNT in the cementitious matrix.

SEM images of UHPCM reinforced with $0.03 \mathrm{wt} . \%$ acid functionalized MWNTs provide strong evidence for the

\section{SN Applied Sciences}




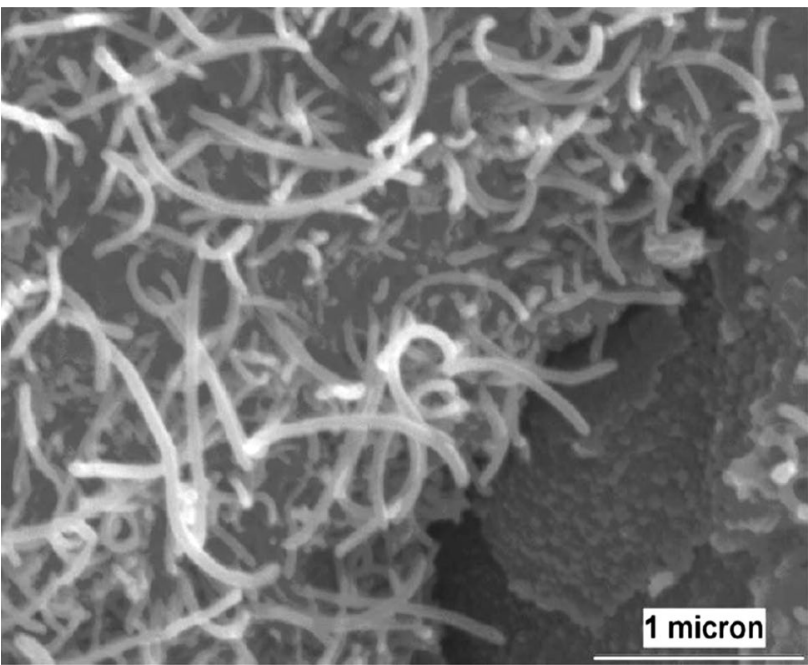

Fig. 13 SEM image of UHPCM reinforced with 0.03 wt.\% CNF-OX, showing CNF pull-out

micro-crack bridging (Fig. 11a-c)) and pull-out actions (Fig. 10b, c) of CNTs, which are key contributions to the flexural strength and flexural toughness of cementitious matrices. Crack bridging and fiber pull-out has been observed previously in CNT reinforced cement composites [10, 38, 58]. SEM images showed (Fig. 12a-c) that CNFs bridge across nano-cracks, and control crack propagation. Microscopic studies by Metaxa et al. also confirmed the current observations [42]. Indications of CNF pull-out from a damage surface after flexure test are shown Fig. 13. SEM image of the morphology of $0.03 \mathrm{wt} . \%$ GNP incorporated UHPCM is shown in Fig. 14. Unlike CNTs and CNFs for which bridges across micro-cracks and nano-cracks were not observed, GNPs seemed to control micro-crack propagation through effectively interacting with the micro-cracks. Figure 14, SEM image of the failed surface of UHPCM reinforced with GNP, provides indications that GNP interact with micro-cracks. Previous studies also confirm a crack filling effect of GNPs in cement matrices [97, 100].

\section{Conclusions}

Carbon based nanomaterials at low weight fraction were evaluated as reinforcement systems in ultra-high-performance cementitious matrices (UHPCM). Emphasis was given to forming compatible surface tethered functional groups on the nanomaterial walls and improved dispersion methods in UHPCM. Surface functionalization followed by the dispersion procedures used in the study at nanomaterials weight fractions of $0.03 \%$ by weight of cement gave significant improvements in properties. SEM

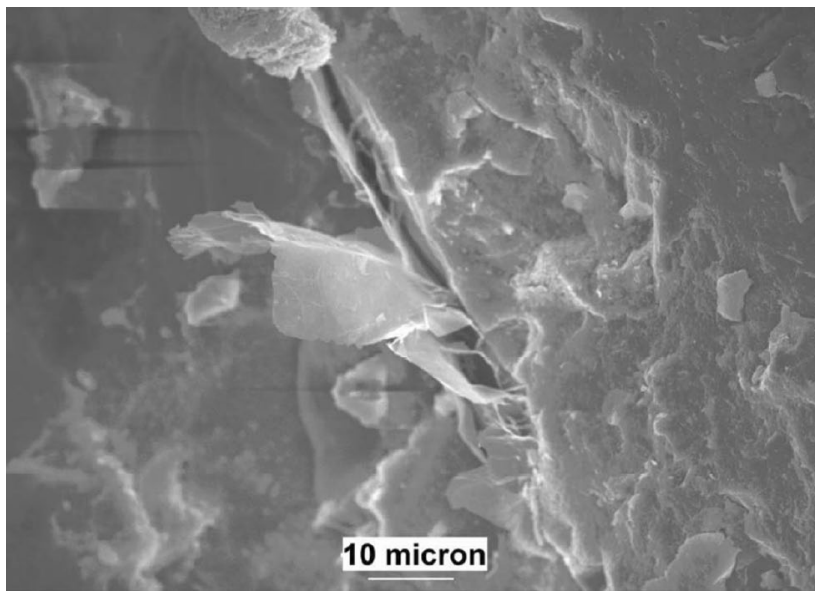

Fig. 14 SEM image of failed surface of UHPCM reinforced with 0.03 wt.\% GNP

studies confirmed uniform dispersion of the nanomaterials in the UHPCM with minimum agglomeration.

Flexural strength and abrasion resistance of UHPCM were greatly increased, by $30 \%$ and $45 \%$ respectively with the incorporation of acid functionalized MWNTs at $0.03 \%$ by weight of cement. Enhancement of flexural strength is important to reduce the brittleness of cement-based materials. The improved flexural strength and energy absorption capacity (flexural toughness) of UHPCM is attributed to the better dispersed acid oxidized MWNTs and enhanced interactions between MWNTs and cement matrix which allows better load transfer. In addition to improvements in mechanical properties, incorporation of GNP at 0.03 wt.\% reduced the moisture sorptivity of cement by $50 \%$. This reflects a gain in moisture barrier qualities of UHPCM that would translate into improved durability characteristics.

Acknowledgements The research reported herein was sponsored by the U.S. Army. The authors thank Dr. Chamila K. Pathirana (Research Scientist) for insightful suggestions pertaining to this manuscript.

Funding The research reported herein was sponsored by the U.S. Army.

\section{Declaration}

Conflicts of interest MMS, PS and AMB are employees of The Metna Company which has a patent in the area of surface functionalization of nanomaterials and their utilization in cementitious matrices.

Open Access This article is licensed under a Creative Commons Attribution 4.0 International License, which permits use, sharing, adaptation, distribution and reproduction in any medium or format, as long as you give appropriate credit to the original author(s) and the source, provide a link to the Creative Commons licence, and indicate if changes were made. The images or other third party material in this article are included in the article's Creative Commons licence, unless 
indicated otherwise in a credit line to the material. If material is not included in the article's Creative Commons licence and your intended use is not permitted by statutory regulation or exceeds the permitted use, you will need to obtain permission directly from the copyright holder. To view a copy of this licence, visit http://creativecommons. org/licenses/by/4.0/.

\section{References}

1. Banthia N, Mindess S, Trorrier J (1996) Impact resistance of steel fiber reinforced concrete. ACI Mater J 93:472-479

2. Brandt AM (2008) Fibre reinforced cement-based (FRC) composites after over 40 years of development in building and civil engineering. Compos Struct 86(1):3-9

3. Han B, Zhang L, Ou J (2017) Smart and multifunctional concrete toward sustainable infrastructures. Springer, Berlin

4. Han B, Yu X, Ou J (2011) Multifunctional and Smart Carbon Nanotube Reinforced Cement-Based Materials. In: Gopalakrishnan K, Birgisson B, Taylor P, Attoh-Okine NO (eds) Nanotechnology in Civil Infrastructure: A Paradigm Shift. Springer, Berlin Heidelberg, Berlin, Heidelberg, pp 1-47. https://doi.org/10.1007/978-3-642-16657-0_1

5. Peyvandi A, Soroushian P, Balachandra AM, Sobolev K (2013) Enhancement of the durability characteristics of concrete nanocomposite pipes with modified graphite nanoplatelets. Constr Build Mater 47:111-117. https://doi.org/10.1016/j. conbuildmat.2013.05.002

6. Nasution A, Imran I, Abdullah M (2015) Improvement of concrete durability by nanomaterials. Procedia Eng 125:608-612

7. Du M, Jing H, Gao Y, Su H, Fang H (2020) Carbon nanomaterials enhanced cement-based composites: advances and challenges. Nanotechnol Rev 9(1):115-135

8. Sanchez F, Sobolev K (2010) Nanotechnology in concrete - A review. Constr Build Mater 24(11):2060-2071. https://doi.org/ 10.1016/j.conbuildmat.2010.03.014

9. Stynoski P, Mondal P, Marsh C (2015) Effects of silica additives on fracture properties of carbon nanotube and carbon fiber reinforced Portland cement mortar. Cement Concr Compos 55:232-240. https://doi.org/10.1016/j.cemconcomp.2014.08. 005

10. Raki L, Beaudoin J, Alizadeh R, Makar J, Sato T (2010) Cement and concrete nanoscience and nanotechnology. Materials 3(2):918-942

11. Jung M, Lee Y-s, Hong S-G, Moon J (2020) Carbon nanotubes (CNTs) in ultra-high performance concrete (UHPC): Dispersion, mechanical properties, and electromagnetic interference (EMI) shielding effectiveness (SE). Cement Concrete Res 131:106017

12. Zhao Z, Qi T, Zhou W, Hui D, Xiao C, Qi J, Zheng Z, Zhao Z (2020) $A$ review on the properties, reinforcing effects, and commercialization of nanomaterials for cement-based materials. Nanotechnol Rev 9(1):303-322

13. Kumar A, Sharma K, Dixit AR (2020) Carbon nanotube- and graphene-reinforced multiphase polymeric composites: review on their properties and applications. J Mater Sci 55(7):2682-2724. https://doi.org/10.1007/s10853-019-04196-y

14. Yu M-F, Lourie O, Dyer MJ, Moloni K, Kelly TF, Ruoff RS (2000) Strength and breaking mechanism of multiwalled carbon nanotubes under tensile load. Science 287(5453):637-640

15. Gao Y, Jing H, Zhou Z, Chen W, Li L, Shi X (2020) Graphene oxideassisted multi-walled carbon nanotube reinforcement of the transport properties in cementitious composites. J Mater Sci 55(2):603-618. https://doi.org/10.1007/s10853-019-04040-3

16. Konsta-Gdoutos MS, Metaxa ZS, Shah SP (2010) Highly dispersed carbon nanotube reinforced cement based materials.
Cem Concr Res 40(7):1052-1059. https://doi.org/10.1016/j. cemconres.2010.02.015

17. Belytschko T, Xiao S, Schatz GC, Ruoff R (2002) Atomistic simulations of nanotube fracture. Phys Rev B 65(23):235430

18. Salvetat J-P, Bonard J-M, Thomson N, Kulik A, Forro L, Benoit W, Zuppiroli L (1999) Mechanical properties of carbon nanotubes. Appl Phys A 69(3):255-260

19. Gao D, Sturm M, Mo Y (2009) Electrical resistance of carbonnanofiber concrete. Smart Mater Struct 18(9):095039

20. Tyson BM, Abu Al-Rub RK, Yazdanbakhsh A, Grasley Z (2011) Carbon nanotubes and carbon nanofibers for enhancing the mechanical properties of nanocomposite cementitious materials. J Mater Civ Eng 23(7):1028-1035

21. Meng W, Khayat KH (2016) Mechanical properties of ultra-highperformance concrete enhanced with graphite nanoplatelets and carbon nanofibers. Compos B Eng 107:113-122

22. Siddique R, Mehta A (2014) Effect of carbon nanotubes on properties of cement mortars. Constr Build Mater 50:116-129. https://doi.org/10.1016/j.conbuildmat.2013.09.019

23. Gillani SS-u-H, Khitab A, Ahmad S, Khushnood RA, Ferro GA, Saleem Kazmi SM, Qureshi LA, Restuccia L (2017) Improving the mechanical performance of cement composites by carbon nanotubes addition. Procedia Struct Integ 3:11-17. https://doi. org/10.1016/j.prostr.2017.04.003

24. Cui X, Han B, Zheng Q, Yu X, Dong S, Zhang L, Ou J (2017) Mechanical properties and reinforcing mechanisms of cementitious composites with different types of multiwalled carbon nanotubes. Compos A Appl Sci Manuf 103:131-147. https:// doi.org/10.1016/j.compositesa.2017.10.001

25. Liew KM, Kai MF, Zhang LW (2016) Carbon nanotube reinforced cementitious composites: An overview. Compos A Appl Sci Manuf 91:301-323. https://doi.org/10.1016/j.compositesa. 2016.10.020

26. Saez de Ibarra Y, Gaitero J, Erkizia E, Campillo I (2006) Atomic force microscopy and nanoindentation of cement pastes with nanotube dispersions. Physica Status solidi (a) 203(6):1076-1081

27. Makar JM, Chan GW (2009) Growth of cement hydration products on single-walled carbon nanotubes. J Am Ceram Soc 92(6):1303-1310

28. Du Y, Yang J, Skariah Thomas B, Li L, Li H, Nazar S (2020) Hybrid graphene oxide/carbon nanotubes reinforced cement paste: An investigation on hybrid ratio. Constr Build Mater 261:119815. https://doi.org/10.1016/j.conbuildmat.2020. 119815

29. Horszczaruk E, Mijowska E, Kalenczuk RJ, Aleksandrzak M, Mijowska S (2015) Nanocomposite of cement/graphene oxide - Impact on hydration kinetics and Young's modulus. Constr Build Mater 78:234-242. https://doi.org/10.1016/j.conbuildmat.2014.12.009

30. Wang J, Dong S, Yu X, Han B (2020) Mechanical properties of graphene-reinforced reactive powder concrete at different strain rates. J Mater Sci 55(8):3369-3387. https://doi.org/10. 1007/s10853-019-04246-5

31. Zhu X, Kang X (2020) Effect of graphene oxide (GO) on the hydration and dissolution of alite in a synthetic cement system. J Mater Sci 55(8):3419-3433. https://doi.org/10.1007/ s10853-019-04266-1

32. Silvestro L, Jean Paul Gleize P (2020) Effect of carbon nanotubes on compressive, flexural and tensile strengths of Portland cement-based materials: A systematic literature review. Constr Build Mater 264:120237. https://doi.org/10.1016/j.conbu ildmat.2020.120237

33. Han B, Yang Z, Shi X, Yu X (2013) Transport Properties of Carbon-Nanotube/Cement Composites. J Mater Eng Perform 22(1):184-189. https://doi.org/10.1007/s11665-012-0228-x 
34. Ruan Y, Han B, Yu X, Zhang W, Wang D (2018) Carbon nanotubes reinforced reactive powder concrete. Compos A Appl Sci Manuf 112:371-382

35. Musso S, Tulliani J-M, Ferro G, Tagliaferro A (2009) Influence of carbon nanotubes structure on the mechanical behavior of cement composites. Compos Sci Technol 69(11):1985-1990. https://doi.org/10.1016/j.compscitech.2009.05.002

36. Rocha VV, Ludvig P, Trindade ACC, de Andrade SF (2019) The influence of carbon nanotubes on the fracture energy, flexural and tensile behavior of cement based composites. Constr Build Mater 209:1-8

37. Sun G, Liang R, Lu Z, Zhang J, Li Z (2016) Mechanism of cement/ carbon nanotube composites with enhanced mechanical properties achieved by interfacial strengthening. Constr Build Mater 115:87-92

38. Li GY, Wang PM, Zhao X (2005) Mechanical behavior and microstructure of cement composites incorporating surface-treated multi-walled carbon nanotubes. Carbon 43(6):1239-1245

39. Mohsen MO, Taha R, Abu Taqa A, Shaat A (2017) Optimum carbon nanotubes' content for improving flexural and compressive strength of cement paste. Constr Build Mater 150:395-403. https://doi.org/10.1016/j.conbuildmat.2017.06.020

40. Al-Rub RKA, Ashour Al, Tyson BM (2012) On the aspect ratio effect of multi-walled carbon nanotube reinforcements on the mechanical properties of cementitious nanocomposites. Constr Build Mater 35:647-655

41. Xu S, Liu J, Li Q (2015) Mechanical properties and microstructure of multi-walled carbon nanotube-reinforced cement paste. Constr Build Mater 76:16-23. https://doi.org/10.1016/j. conbuildmat.2014.11.049

42. Metaxa ZS, Konsta-Gdoutos MS, Shah SP (2010) Carbon nanofiber-reinforced cement-based materials. Transp Res Rec 2142(1):114-118

43. Konsta-Gdoutos MS, Danoglidis PA, Falara MG, Nitodas SF (2017) Fresh and mechanical properties, and strain sensing of nanomodified cement mortars: The effects of MWCNT aspect ratio, density and functionalization. Cement Concr Compos 82:137-151. https://doi.org/10.1016/j.cemconcomp.2017.05. 004

44. Zhan M, Pan G, Zhou F, Mi R, Shah SP (2020) In situ-grown carbon nanotubes enhanced cement-based materials with multifunctionality. Cement Concr Compos 108:103518. https://doi. org/10.1016/j.cemconcomp.2020.103518

45. Kirgiz MS (2015) Advance treatment by nanographite for Portland pulverised fly ash cement (the class F) systems. Compos B Eng 82:59-71

46. Xie X-L, Mai Y-W, Zhou X-P (2005) Dispersion and alignment of carbon nanotubes in polymer matrix: a review. Mater Sci Eng R Rep 49(4):89-112

47. Li GY, Wang PM, Zhao X (2007) Pressure-sensitive properties and microstructure of carbon nanotube reinforced cement composites. Cement Concr Compos 29(5):377-382

48. Balasubramaniam B, Mondal K, Ramasamy K, Palani GS, lyer NR (2017) Hydration phenomena of functionalized carbon nanotubes (CNT)/cement composites. Fibers 5(4):39

49. Hu Y, Luo D, Li P, Li Q, Sun G (2014) Fracture toughness enhancement of cement paste with multi-walled carbon nanotubes. Constr Build Mater 70:332-338. https://doi.org/10.1016/j. conbuildmat.2014.07.077

50. Konsta-Gdoutos MS, Metaxa ZS, Shah SP (2010) Multi-scale mechanical and fracture characteristics and early-age strain capacity of high performance carbon nanotube/cement nanocomposites. Cement Concr Compos 32(2):110-115

51. Luo J, Duan Z, Li H (2009) The influence of surfactants on the processing of multi-walled carbon nanotubes in reinforced cement matrix composites. Physica Status Solidi (a) 206(12):2783-2790. https://doi.org/10.1002/pssa.200824310

52. Krause B, Mende M, Pötschke P, Petzold G (2010) Dispersability and particle size distribution of CNTs in an aqueous surfactant dispersion as a function of ultrasonic treatment time. Carbon 48(10):2746-2754. https://doi.org/10.1016/j.carbon.2010.04. 002

53. Rausch J, Zhuang R-C, Mäder E (2010) Surfactant assisted dispersion of functionalized multi-walled carbon nanotubes in aqueous media. Compos A Appl Sci Manuf 41(9):1038-1046

54. Vaisman L, Wagner HD, Marom G (2006) The role of surfactants in dispersion of carbon nanotubes. Adv Coll Interface Sci 128:37-46

55. Collins F, Lambert J, Duan WH (2012) The influences of admixtures on the dispersion, workability, and strength of carbon nanotube-OPC paste mixtures. Cement Concr Compos 34(2):201-207. https://doi.org/10.1016/j.cemconcomp.2011. 09.013

56. Stephens C, Brown L, Sanchez F (2016) Quantification of the re-agglomeration of carbon nanofiber aqueous dispersion in cement pastes and effect on the early age flexural response. Carbon 107:482-500

57. Metaxa Z (2015) Polycarboxylate based superplasticizers as dispersant agents for exfoliated graphene nanoplatelets reinforcing cement based materials. J Eng Sci Technol Rev 8(5):1-5

58. Cwirzen A, Habermehl-Cwirzen K, Penttala V (2008) Surface decoration of carbon nanotubes and mechanical properties of cement/carbon nanotube composites. Adv Cem Res 20(2):65-73

59. Wang B, Pang B (2020) Properties improvement of multiwall carbon nanotubes-reinforced cement-based composites. J Compos Mater 54(18):2379-2387

60. Chen Z, Lim JLG, Yang E-H (2016) Ultra high performance cement-based composites incorporating low dosage of plasma synthesized carbon nanotubes. Mater Des 108:479-487. https://doi.org/10.1016/j.matdes.2016.07.016

61. Sadiq MM (2013) Reinforcement of cement-based matrices with graphite nanomaterials (Doctoral dissertation). Michigan State University, Lansing, MI, Doctoral

62. ASTM C150 "Standard Specification for Portland Cement" (2020). ASTM International, West Conshohocken, PA

63. Peyvandi A, Soroushian P, Abdol N, Balachandra AM (2013) Surface-modified graphite nanomaterials for improved reinforcement efficiency in cementitious paste. Carbon 63:175-186

64. ASTM C192 "Standard Practice for Making and Curing Concrete Test Specimens in the Laboratory" (2019) ASTM International, West Conshohocken, PA

65. ASTM C 305 "Standard Practice for Mechanical Mixing of Hydraulic Cement Pastes and Mortars of Plastic Consistency" (2020) ASTM International, West Conshohocken, PA

66. Alani AH, Johari MAM, Aldahdooh MAA, Muhamad Bunnori N (2019) Development of engineering and transport properties of green high strength concrete utilizing ternary blended binders. Eur J Environ Civil Eng:1-17. doi:https://doi.org/10.1080/ 19648189.2019.1573381

67. ASTM C109 "Standard test method for compressive strength of hydraulic cement mortars (Using 2-in. or [50 mm] Cube Specimens)" (2020). ASTM International, West Conshohocken, PA

68. ASTM C348 "Standard test method for flexural strength of hydraulic-cement mortars" (2018). ASTM International, West Conshohocken, PA

69. Chen P-W, Chung DDL (1993) Concrete reinforced with up to 02 vol\% of short carbon fibres. Composites 24(1):33-52. https:// doi.org/10.1016/0010-4361(93)90261-6 
70. ASTM C944 "standard test method for abrasion resistance of concrete or mortar surfaces by the rotating-cutter method" (2019) ASTM International, West Conshohocken, PA

71. ASTM C1585 "Standard test method for measurement of rate of absorption of water by hydraulic-cement concretes" (2004) ASTM International, West Conshohocken, PA

72. Bokobza L, Zhang J (2012) Raman spectroscopic characterization of multiwall carbon nanotubes and of composites. Express Polym Lett 6(7):601-608

73. Esmaeili J, Mohammadjafari A (2014) Increasing flexural strength and toughness of cement mortar using multi-walled Carbon nanotubes. Int J Nano Dimension 5(4):300-407

74. Keyvani A (2007) Huge opportunities for industry of nanofibrous concrete technology. Int J Nanosci Nanotechnol 3(1):3-12

75. Lee C, Wei X, Kysar JW, Hone J (2008) Measurement of the elastic properties and intrinsic strength of monolayer graphene. Science 321(5887):385-388

76. Wang B, Pang B (2019) Mechanical property and toughening mechanism of water reducing agents modified graphene nanoplatelets reinforced cement composites. Constr Build Mater 226:699-711. https://doi.org/10.1016/j.conbuildmat.2019.07. 229

77. Wang B, Shuang D (2019) Effect and mechanism of graphene nanoplatelets on hydration reaction, mechanical properties and microstructure of cement composites. Constr Build Mater 228:116720. https://doi.org/10.1016/j.conbuildmat.2019. 116720

78. Saafi M, Tang L, Fung J, Rahman M, Liggat J (2015) Enhanced properties of graphene/fly ash geopolymeric composite cement. Cem Concr Res 67:292-299. https://doi.org/10.1016/j. cemconres.2014.08.011

79. Ranjbar N, Mehrali M, Mehrali M, Alengaram UJ, Jumaat MZ (2015) Graphene nanoplatelet-fly ash based geopolymer composites. Cem Concr Res 76:222-231. https://doi.org/10.1016/j. cemconres.2015.06.003

80. Pan Z, He L, Qiu L, Korayem AH, Li G, Zhu JW, Collins F, Li D, Duan WH, Wang MC (2015) Mechanical properties and microstructure of a graphene oxide-cement composite. Cement Concr Compos 58:140-147. https://doi.org/10.1016/j.cemco ncomp.2015.02.001

81. Dhir RK, de Brito J, Silva RV, Lye CQ (2019) Use of Recycled Aggregates in Road Pavement Applications. In: Dhir RK, de Brito J, Silva RV, Lye CQ (eds) Sustainable Construction Materials. Woodhead Publishing, Cambridge, pp 451-494. https://doi. org/10.1016/B978-0-08-100985-7.00012-1

82. Salvetat-Delmotte J-P, Rubio A (2002) Mechanical properties of carbon nanotubes: a fiber digest for beginners. Carbon 40(10):1729-1734

83. Waters J, Guduru P, Jouzi aM, Xu J, Hanlon T, Suresh S (2005) Shell buckling of individual multiwalled carbon nanotubes using nanoindentation. Appl Phys Lett 87(10):103109

84. He XQ, Kitipornchai S, Liew KM (2005) Buckling analysis of multi-walled carbon nanotubes: a continuum model accounting for van der Waals interaction. J Mech Phys Solids 53(2):303326. https://doi.org/10.1016/j.jmps.2004.08.003
85. Sears A, Batra RC (2006) Buckling of multiwalled carbon nanotubes under axial compression. Phys Rev B 73(8):085410. https://doi.org/10.1103/PhysRevB.73.085410

86. Zhang YQ, Liu GR, Wang JS (2004) Small-scale effects on buckling of multiwalled carbon nanotubes under axial compression. Phys Rev B 70(20):205430. https://doi.org/10.1103/PhysRevB. 70.205430

87. Sobolkina A, Mechtcherine V, Khavrus V, Maier D, Mende M, Ritschel M, Leonhardt A (2012) Dispersion of carbon nanotubes and its influence on the mechanical properties of the cement matrix. Cement Concr Compos 34(10):1104-1113. https://doi. org/10.1016/j.cemconcomp.2012.07.008

88. Zhang LC, Zarudi I, Xiao KQ (2006) Novel behaviour of friction and wear of epoxy composites reinforced by carbon nanotubes. Wear 261(7):806-811. https://doi.org/10.1016/j.wear. 2006.01.033

89. Gao Y, He B, Li Y, Tang J, Qu L (2017) Effects of nano-particles on improvement in wear resistance and drying shrinkage of road fly ash concrete. Constr Build Mater 151:228-235

90. Hassan MM, Dylla H, Mohammad LN, Rupnow T (2010) Evaluation of the durability of titanium dioxide photocatalyst coating for concrete pavement. Constr Build Mater 24(8):1456-1461. https://doi.org/10.1016/j.conbuildmat.2010.01.009

91. Wang D, Zhang W, Ruan Y, Yu X, Han B (2018) Enhancements and mechanisms of nanoparticles on wear resistance and chloride penetration resistance of reactive powder concrete. Constr Build Mater 189:487-497

92. Grdic ZJ, Curcic GAT, Ristic NS, Despotovic IM (2012) Abrasion resistance of concrete micro-reinforced with polypropylene fibers. Constr Build Mater 27(1):305-312

93. Kabay N (2014) Abrasion resistance and fracture energy of concretes with basalt fiber. Constr Build Mater 50:95-101

94. Sebök T, Stráněl O (2004) Wear resistance of polymer-impregnated mortars and concrete. Cem Concr Res 34(10):1853-1858

95. Compton OC, Kim S, Pierre C, Torkelson JM, Nguyen ST (2010) Crumpled graphene nanosheets as highly effective barrier property enhancers. Adv Mater 22(42):4759-4763

96. Wang B, Jiang R, Wu Z (2016) Investigation of the Mechanical Properties and Microstructure of Graphene NanoplateletCement Composite. Nanomaterials 6(11):200

97. Wang B, Shuang D (2018) Effect of graphene nanoplatelets on the properties, pore structure and microstructure of cement composites. Mater Express 8(5):407-416

98. Du H, Dai Pang S (2015) Enhancement of barrier properties of cement mortar with graphene nanoplatelet. Cem Concr Res 76:10-19

99. Gong J, Lin L, Fan S (2020) Modification of cementitious composites with graphene oxide and carbon nanotubes. SN Applied Sciences 2(9):1-16

100. Tabatabaei M, Taleghani AD, Alem N (2020) Nanoengineering of cement using graphite platelets to refine inherent microstructural defects. Composites Part B: Eng 202:108277

Publisher's Note Springer Nature remains neutral with regard to jurisdictional claims in published maps and institutional affiliations. 